DOI: 10.12731/2658-4034-2020-3-55-61

\title{
ГЕНЕЗИС ПОНЯТИЯ ПЕДАГОГИЧЕСКОЙ ТЕХНОЛОГИИ
}

\author{
Шехмирзова А.М., Грибина Л.В.
}

ФГБОУ ВО «Адыгейский государственный университет»,

г. Майкоп, Республика Адыгея, Российская Федерация

В статье исследуется вопрос истории возникновения педагогической технологии как понятия и направления педагогической науки. Раскрывается сущность педагогической технологии, начиная со времен Я.А. Коменского до наших дней. Показывается эволючионное развитие родовых понятий к термину педагогическая технология.

Ключевые слова: педагогическая технология; эволючионное развитие; образовательные технологии; технология обучения; информационные технологии; технологии дистанциионного образования; мультимедийнье технологии.

\section{GENESIS OF THE CONCEPT OF PEDAGOGICAL TECHNOLOGY}

\author{
Shekhmirzova A.M., Gribina L.V. \\ Adyghe State University, Maikop, Adygea Republic, \\ Russian Federation
}

The article examines the issue of the history of the emergence of pedagogical technology as a concept and direction of pedagogical science. The essence of pedagogical technology is revealed, starting from the time of Y.A. Comenius to the present day. The evolutionary development of generic concepts to the term pedagogical technology is shown. 
Keywords: pedagogical technology; evolutionary development; educational technology; teaching technology; information technology; distance education technologies; multimedia technologies.

Исторически понятие «педагогическая технология» возникло в связи с техническим прогрессом и вошло в лексикон педагогической науки под влиянием развития промышленного производства, где бурно использовались технологические идеи. В ходе эволюционного развития это понятие претерпевало изменения, уточнялось его содержание. Так, в педагогике этот термин, имевший промышленное происхождение, получил развитие не сразу, хотя идея о возможности управления процессом обучения и воспроизводимости его результатов прослеживалась еще в трудах Я.А. Коменского.

Со времен Коменского было немало попыток сделать обучение похожим на хорошо налаженный механизм. Сам Коменский стремился отыскать такой порядок в обучении, который неминуемо приводил бы к положительным результатам. Он отмечал необходимость овладения педагогом таким инструментарием, который позволял бы повысить результативность педагогической работы. Его идеи создания технологии, напоминавшие поточное производство образованных людей, были выстроены им в стройную классно-урочную систему организации процесса обучения. Созданная им система обучения (объяснительно-иллюстративное) способствовала стимулированию развития наук за счет жесткой предметной организации и позволяла организовать обучение вокруг объективного непрерывно накапливающегося знания. Коменский стремился найти такой порядок обучения, при котором оно осуществлялось бы по единым законам человеческой природы [2]. Тогда обучение потребовало бы только «искусного распределения времени, предметов и метода». В своем труде «Великая дидактика» он обосновывает в качестве одной из ведущих задач теории обучения и образования (дидактики) - «всех учить всему», но учить с верным успехом, с гарантированным результатом. Так он впервые сформулировал одну из важнейших технологических идей - гарантированность результата с быстро- 
той обучения («учить быстро»). Механизм обучения, приводящий к результативности процесса обучения, он назвал «дидактической машиной». Методологическим ориентиром для Коменского выступал принцип природосообразности. В его основе он рассматривал природу в целом, включая и человека, который в своем развитии подчинен тем же законам, что и внешняя природа.

Начало своего развития «педагогические технологии» получили в 40-ые годы, когда начали использование достижений инженерной мысли в учебном процессе. В 50-60 гг. ХХ в. учебно-воспитательный процесс технических вузов стали внедрять аудиовизуальные и технические средства обучения. В те годы применялся термин «технология в обучении», под которым понималось его технизация, связанная с применением различных ТСО. С «технизацией» обучения связывались немалые надежды на преобразование практики массового обучения. С 1954 года в педагогический процесс стали внедрять программированное обучение. Тогда применение обучающих программ способствовало появлению терминов «технология образования» и «образовательные технологии» (как синонимы). В программированном обучении стало возможным широкое использование технических средств для подачи учебной информации, тренировки и контроля знаний учащихся посредством тестов.

В начале 60-х годов XX столетия в связи с реформированием вначале американской, а затем и европейской школы происходит массовое внедрение в учебный процесс технических средств с целью усовершенствования учебного процесса. Это событие привело к появлению термина «технология обучения», который использовался как синоним «педагогических технологий». Появление многочисленных трудов по этой проблеме внесли коррективы в его понимание. Термин «педагогические технологии» в широком смысле стал пониматься как проект инновационного, более эффективного педагогического процесса, реализуемого педагогом в дидактическом взаимодействии с обучаемым с охватом всех компонентов учебного процесса. В таком широком понимании стало возможным рассмотрение педагогической технологии как родового понятия по отношению к другим 
терминам: «технология в образовании», «технология образования», «образовательные технологии», «технология обучения», «технологии в воспитании» (в таком сочетании правомерны возражения педагогов о невозможности технологизации процесса воспитания).

С конца 1970 гг. под воздействием системного подхода уточняется общая установка педагогической технологии: решать дидактические проблемы по пути управления учебным процессом с точно заданными целями, достижение которых должно поддаваться четкому описанию и определению. В XIX - XX вв. получают распространение информационные технологии. Переход от индустриального к постиндустриальному (информационному) обществу ознаменовался бурным развитием телекоммуникационной сети Интернет. Поскольку в обществе информация стала иметь стратегическую ценность, возникла необходимость обеспечить более эффективные способы ее создания, хранения и переработки. Ускорение научно-технического прогресса отразилось на всех сферах общественного развития, и прежде всего на системе образования, что выразилось в появлении разнообразных теорий по этой проблеме. В таких условиях термин «педагогическая технология», понимаемый как заранее спроектированный учебный процесс, получает дальнейшее эволюционное развитие, что позволило говорить о практической реализации концепции информатизации образования. В свою очередь, это поставило перед педагогической системой новые задачи, обусловленные требованиями современного общества. В обучении, который всегда сопровождается обменом информацией между субъектами образовательного процесса, педагог перестает быть основным источником и транслятором информации. Перед ним теперь встает проблема поиска методов эффективного управления учебно-познавательной деятельностью обучающихся при работе с большими информационными ресурсами.

В XXI в. происходит распространение и внедрение в учебный процесс компьютерных технологий, постепенно охватывающее практически все развитые страны, включая Россию. Эти годы способствовали расширению базы педагогических технологий и появлению впоследствии в этом русле других терминов. 
Новый этап научно-технического развития в обществе кон. XX нач. XXI в. сопровождается уточнением понятий «компьютерные технологии» и «информационные технологии», связанные с широкими возможностями современных вычислительных средств. Появляется термин «технологии дистанционного образования» [3]. Правомерным стало употребление «компьютерных технологий» как средства обучения, связанного с различными программами. Его внедрение в образовательный процесс постепенно позволяет автоматизировать отдельные его звенья, тем самым существенно повышать эффективность обучения.

Сегодня научно-технический прогресс открывает новые возможности усовершенствования системы образования в целом. Повышение скорости передачи информации делают реальным применение новых мультимедийных технологий в образовательном процессе. Так, научнотехнический прогресс оказывающий влияние на становление понятия «педагогических технологий» постоянно расширяет его понимание. Несомненно, что массовое внедрение технических средств в учебный процесс позволит повысить эффективность обучения на основе его управляемости. Однако важным является и определение их функционального назначения (места, роли технических средств) в процессе обучения. Поскольку только умелое владение новыми техническими средствами, наряду со знанием общих закономерностей процесса обучения и владения новыми методами передачи содержания образования может обеспечить повышение качества образования в целом.

Необходимость решения дидактических задач по управлению учебным процессом с точно заданными целями, достижение которых поддается описанию и определению, приводит сегодня к дальнейшему развитию и распространению педагогических технологий.

К наиболее известным авторам педагогических технологий за рубежом относят Дж. Кэролла, Б. Блума, Д. Брунера и др., а в отечественной практике технологические подходы к обучению отражены в научных трудах П.Я. Гальперина, Н.Ф. Талызиной, Ю.К. Бабанского, М.В. Кларина и др. Начало развитию технологий воспитания положено в работах И.П. Ивановой, Н.Е. Щурковой, Л.Ф. Спириной, Ж.Е. Заводской, З.В. Артеменко и др. 
Теоретические аспекты педагогических технологий подробно описаны в работе академика В.П.Беспалько. Его труд «Слагаемые педагогической технологии» [1] способствовал появлению представлений о педагогической технологии как о систематичном и последовательном воплощении на практике заранее спроектированного учебно-воспитательного процесса. Поскольку описание любого учебно-воспитательного процесса представляет собой описание некоторой педагогической системы, то педагогическая технология определяется им как проект определенной педагогической системы, реализуемой на практике.

Следует иметь в виду, что понятие «педагогическая технология» является абстракцией, служащей для понимания реально существующего педагогического явления. И на сегодняшний день актуальным является осмысление его как научного понятия педагогики, в частности дидактики. В педагогической литературе на сегодняшний день можно найти множество определений этого понятия, авторы которых различно представляют структуру и составляющие технологического процесса. В нашем понимании педагогическая технология рассматривается как проект определенной педагогической системы, реализуемой на практике и гарантирующий достижение образовательных целей. Поскольку реализация проекта на практике происходит в действиях педагога, то правомерно и другое определение ПТ. Педагогическая технология - это систематическое и последовательное воплощение педагогом на практике заранее спроектированного управляемого учебного процесса, гарантирующего достижение учащимися запланированного результата обучения.

Само развитие педагогической технологии как понятия и направления в педагогической науке соответствует педагогическим эпохам, в каждом из которых оно обогащается и приобретает новые качества и свойства. В истории педагогики таких эпох было несколько [1]:

I - эпоха педагогической деятельности индивидуального педагога, работающего «вручную», без каких-либо технических средств;

II - эпоха учебной книги;

III - эпоха аудиовизуальных средств; 
IV - эпоха простых средств автоматизации управления обучением;

$\mathrm{V}$ - эпоха адаптивных средств автоматизации управления обучением на базе ЭВМ;

VI - эпоха адаптивных средств автоматизации управления обучением на базе современных компьютерных средств.

Для каждой эпохи характерны свои технологии. Пожалуй, самой трудной является технология эпохи I, для которой характерно ограниченность средств осуществления процесса обучения. Необыкновенная трудоемкость для педагога этой эпохи ограничивает достигаемое качество подготовки обучаемых. По мере научно-технического развития появляются новые средства обучения, способствующие последовательному переходу к другой эпохе. Смена эпох сопровождается эволюцией понятия «педагогическая технология». Благодаря ее развитию и совершенствованию с каждой новой педагогической эпохой труд педагога становится более посильным и повышается его эффективность. Современный исторический момент времени сопровождается эпохальным сдвигом в обучении и понимании педагогической технологии.

\section{Список литературы}

1. Беспалько В.П. Слагаемые педагогической технологии. М.: Педагогика, 1989. 192 с.

2. Кларин М.В. Педагогическая технология в учебном процессе. Анализ зарубежного опыта. М.: Знание, 1989. 80 с.

3. Чернилевский Д.В. Дидактические технологии в высшей школе. М.: ЮНИТИ-ДАНА, 2002. 437 с.

\section{References}

1. Bespal'ko V.P. Slagaemye pedagogicheskoy tekhnologii. M.: Pedagogika, 1989. $192 \mathrm{~s}$.

2. Klarin M.V. Pedagogicheskaya tekhnologiya v uchebnom protsesse. Analiz zarubezhnogo opyta. M.: Znanie, 1989. 80 s.

3. Chernilevskiy D.V. Didakticheskie tekhnologii v vysshey shkole. M.: YuNITI-DANA, 2002. $437 \mathrm{~s}$. 